Acta Poetica $35 \cdot 2$

JULIO-DICIEMBRE

$2014(35-49)$

\title{
La armonía del devenir: zen y poesía en Juan L. Ortiz
}

\author{
Tania Favela Bustillo
}

En este ensayo exploro la relación que existe en la poesía del poeta argentino Juan L. Ortiz, entre la experiencia poética y la iluminación o satori de la filosofía zen. Juan L. Ortiz, por medio de la contemplación de su paisaje natalcotidiano, logra acceder a un nivel de conciencia en el que entrevé la maravilla de la compenetración del uno con el todo. La renuncia a sí mismo, la atención hacia las cosas por más ínfimas que éstas sean, la aceptación del vacío como fundamento de la existencia, lo llevan a ver al amor como la única respuesta para recobrar su propia armonía.

La poesía para Ortiz supone entonces la posibilidad de acceder, mediante el leguaje, a esa armonía tan deseada. Un eje importante de este ensayo es el de mostrar cómo el lenguaje de Ortiz logra configurar en su interior esa experiencia, cómo construye un lenguaje que él mismo calificó de "transparente", y cómo ese lenguaje logra contener en sí la armonía del devenir.

PALABRAS CLAVE: poesía, zen, armonía, Juan L. Ortiz.

I am exploring in this essay the relation in Argentinian poet Juan L. Ortiz's poetry, between the poetic experience and the zen philosophy of enlightenment or satori. Through the contemplation of the landscape in his everyday fatherland, Juan L. Ortiz reaches consciousness in which he perceives the wonder of one being one with everything. Renouncement of one's self, attention to the smallest of things, acceptance of the void as basis of our existence, take him to see love as the only answer to recover harmony.

Ortiz's poetry gives then the possibility to enter, through language, to that harmony he so aspires. An important axis in this essay is to present how Ortiz's language succeeds to configure within itself that experience, how he builds 
up a language which he himself denominated "transparent", and how this language contains within itself the harmony of becoming.

KEYWORDS: poetry, zen, harmony, Juan L. Ortiz.

Fecha de recepción: 5 de junio de 2013

Fecha de aceptación: 20 de enero de 2014 


\author{
Tania Favela Bustillo \\ Universidad Iberoamericana
}

\title{
La armonía del devenir: zen y poesía en Juan L. Ortiz
}

\begin{abstract}
Cuando escribo, sencillamente me dejo llevar por las cosas y por el ánimo. Es como el cielo vacío que se irisa cuando aparece el arco iris, o que al salir el sol resplandece. El cielo vacío, por su naturaleza no es ni luminoso ni florido en colores. Sobre mi espíritu, igual a este cielo vacío, han aparecido y se han coloreado escenas diversas, sin dejar huella alguna.
\end{abstract}

SAIGYO

Quiero comenzar recordando un cuento taoísta conocido como "El arpa de Lung Men":

Hace mucho tiempo, en el barranco de Lung Men, se alzaba un hermoso árbol Kiri. Se dice que era tan alto que podía conversar con el cielo y las estrellas, y que sus raíces eran tan profundas que sus anillos de bronce se mezclaban con los del dragón de plata que dormía debajo de la tierra. Un día un mago transformó al árbol en arpa, el instrumento era maravilloso, pero según dijo el mago, sólo podría ser tocado por el más grande de los músicos. El emperador de China guardó el arpa como un tesoro, muchos fueron los músicos invitados que de todas partes llegaban para tratar de tocar en ella algunas melodías, pero a pesar de sus esfuerzos, del arpa sólo salían notas ásperas y chirriantes. Después de muchos años llegó Pai Ya, el príncipe de los arpistas. Pai Ya se sentó en silencio frente al emperador, tomó el instrumento con ternura y con mano suave lo acarició. Melodías bellísimas resonaban en el arpa despertando el recuerdo 
de la madera. Pai Ya cantó sobre el viento y las montañas, sobre las estrellas y el rocío. Cantó sobre el cambio de las estaciones, y la brisa de la primavera, los insectos del verano, la luna del otoño y la nieve entre las ramas cantaban al unísono con él. Cantó sobre la guerra y el dolor, sobre el amor y la dulzura. La armonía de las notas no dejaba nada afuera y todos se extasiaban al escucharlo. Cuando Pai Ya terminó de tocar, el emperador le preguntó cuál era su secreto, ¿cómo es que había logrado tocar tan bellas melodías? Pai Ya le respondió: "Majestad, los demás han fracasado porque no cantaban sino sobre sí mismos. Yo he dejado que el arpa eligiera libremente sus temas y no sabía realmente si el arpa era Pai Ya o Pai Ya era el arpa".

Cito el cuento completo porque Juan L. Ortiz al final de su poema "deja las letras...", que se encuentra en su libro De las raíces y del cielo, alude a esta historia. La mención que hace Ortiz del "arpa de Lungmen" revela matices importantes de su poética: en primer lugar muestra sus vínculos con Oriente, principalmente con el taoísmo y su legítimo sucesor, el budismo zen, y señala también su particular concepción del lenguaje poético y del papel que la poesía y el poeta tienen dentro de la sociedad y dentro del universo:

\section{$[\ldots]$}

Hay que perder a veces "la ciudad" y hay que perder a veces "las letras" para reencontrarlas sobre el vértigo, más puras

en las relaciones de los orígenes...

O más ligeras, si prefieres, como en ese domingo

y en esa fantasía que serán...

Hay que perder los vestidos y hay que perder la misma identidad para que el poema, deseablemente anónimo, siga a la florecilla que no firma, no, su perfección en la armonía que la excede...

O para ser el arpa de Lungmen eligiendo ella sola los temas de su música, lejos de los tañedores que se cantan a sí mismos

1 Versión libre del cuento "El arpa de Lung Men", tomando como base el cuento relatado por Okakura Kakuzo en El libro del té, 71. 
o que no oyen con los suyos a los recuerdos de las ramas ni lo que dice el viento...

ni menos ven lo que el viento, por ahí, pone de pie...

Y aquí además, las rimas entre los escalofríos de las briznas, con los hilos temblando, siempre más allá de nuestra luz...

$\mathrm{Y}$ el rostro de Ella no escrito, oh, recién nacido, con unos signos por hallar y que serán, oh amigo, los que han de llevarte hasta su esencia como las mismas, las mismas letras de tu alma...

Pero la viste a Ella, amaneciendo aquí, Ella, de la espuma de las matas, Venus de las colinas. Ella, sobre un flujo de jardín, virgen profunda ésta toda aún de cabellos? [...]

Perder la propia identidad y permitir que el instrumento toque libremente sus melodías. En el cuento taoísta, el arpa y Pai Ya son uno mismo, no hay un arpa y un arpista sino el encuentro, la fusión de ambos. Lo mismo propone al final del poema Juan L. Ortiz, que el poeta y el lenguaje se fundan en una misma melodía, respondan a una misma armonía. "Deja las letras y deja la ciudad..." escribe Juan L. Ortiz al inicio de su poema, aconsejándole al poeta que renuncie a lo que ya conoce; que renuncie tanto a la idea de "Literatura" como a las comodidades de la ciudad y se interne, por decirlo así, en el misterio de la naturaleza y de la poesía: "No estás tú también / un poco sucio de letras y un poco sucio de ciudad? / Hay que perder a veces 'la ciudad' y hay que perder a veces 'las letras'/ para reencontrarlas sobre el vértigo, más puras en las relaciones de los orígenes..." (162). En ambos textos, en el cuento y en el poema, se pone en evidencia la importancia de fluir con el decurso de las cosas, sin intentar imponer la propia voluntad; adaptarse al instrumento y fluir con sus armonías, para poder escuchar las otras voces y cantar al unísono con ellas. Al igual que la madera del arpa, las palabras

${ }^{2}$ En general todas las referencias a los poemas de Juan L. Ortiz pertenecen a la antología En el aura del sauce, publicada por la Universidad Autónoma de Puebla. Cuando se cite de otro libro se hará la pertinente aclaración. 
poseen vida y memoria, y el poeta, desde la perspectiva de Ortiz, debe saber borrarse a sí mismo para que esas otras voces, distintas y al mismo tiempo próximas a la suya, se tejan en el poema.

Para Juan L. Ortiz la poesía es naturaleza y el lenguaje una herramienta que permite al poeta acercarse a, o alejarse de, esa naturaleza. En este sentido el lenguaje puede ser prisión o puerta de acceso. Indiscutiblemente Ortiz busca que su lenguaje sea puerta de acceso, que el universo pueda penetrar las palabras, que las palabras se reintegren en la naturaleza, y que su yo se filtre y a la vez se diluya al interior del lenguaje. La aspiración de Ortiz es muy alta y muy compleja, que él mismo sintetiza en una entrevista realizada por Bignozzi en 1969: "yo quisiera hacer una cosa completamente transparente, invisible casi. Donde no hubiera ni siquiera imagen, ni mención o apenas mencionar, eso sería lo ideal". En otra entrevista realizada por Jorge Conti en 1972, Ortiz vuelve a mencionar "la transparencia" como fundamento de su lenguaje poético:

JC: ¿Cómo definiría, entonces, la función poética del lenguaje, Juan? ¿Cuándo puede hablarse de lenguaje poético?

JLO: Cuando es utilizado de una manera diríamos... (claro, hay que hablar de una manera, en cierto modo religiosa) de "iluminación"... Es decir, se carga tanto, pone en función tantas virtualidades fonéticas, conceptuales, rítmicas, que paradójicamente y a la vez se hace transparente y recibe (justamente ahí está la doctrina Zen), por hacerse casi inexistente, recibe, digo, ciertas esencias, ciertas atmósferas, ciertos aires de la realidad que al hombre se le escapan... y que no puede asir (73).

La trasparencia del lenguaje a la que aspira Ortiz nos lleva a pensar en la disolución de las fronteras entre la palabra y su significado, entre el lenguaje y el mundo, y entre el yo y los otros. Nos lleva a pensar en la no-mente (mushin) o el vacío zen, que puede entenderse como un estado de apertura, de disponibilidad, en el que el hombre renuncia a sí mismo para abarcarlo todo y al mismo tiempo en ese todo reencontrarse a sí mismo. "Todo depende de cómo uno renuncie a su propia mente" (Suzuki, El zen y la cultura japonesa, 73), dice una sentencia zen. Se debe renunciar entonces a la mente ordinaria, a la mente que se estanca, que se detiene y, por lo tanto, a la mente que se divide, que fragmenta la 
realidad; no a la mente total, que es a la que apelan tanto Pai Ya como Juan L. Ortiz. La mente total es la mente que retorna a su estado de fluidez y que sigue el impulso, el ritmo, la respiración del universo. La mente total supone el vaciamiento de la subjetividad y la desfragmentación de la realidad.

El cuento zen "Una taza de té" nos habla de ese vaciamiento que se necesita para recibir el mundo, de esa mente total que no discrimina y retorna a su naturaleza que es, en última instancia, el vacío:

Nan-in, maestro japonés que vivió en la era Meiji recibió a un profesor universitario que había acudido a informarse sobre el zen.

Nan-in sirvió el té. Llenó la taza de su visitante, y siguió vertiéndolo.

El profesor se quedó mirando el líquido derramarse, hasta que no pudo contenerse:

-Está llena la taza. ¡Ya no cabe más!

-Como esta taza -dijo Nan-in-, está usted lleno de sus propias opiniones y especulaciones. ¿Cómo puedo mostrarle el zen si no vacía su taza antes? (Reps, 19).

Juan L. Ortiz, como esa taza vacía, libre de todo apego, de toda distorsión emocional o intelectual, puede llegar al lenguaje y entablar desde ahí un diálogo con la naturaleza y con los otros hombres: los cerros, el río, los árboles, las pequeñas yerbas, las flores, los hombres, el cielo, el horizonte, el grillo, todo tiene algo que decir, todo murmura y ese murmullo, mezcla de amor y de dolor, de asombro y de tristeza, encuentra su registro perfecto en las palabras de Ortiz: “¿Qué nos quiere decir el cerco crepuscular?, ¿Qué quieren decir / esas figuras humildes / qué descienden / medio perdidas como el cerco?” (77), “Qué nos pregunta el vago / horizonte que se viene a nuestra melancolía / lleno de gestos mojados [...]" (19), “QQué invisible ave nostálgica llama? / ¿Es el aire que canta? /¿O es la soledad infantil / pero profunda [...]", (30) "Escucháis la voz de la noche?”(56), ¿Qué alma, eterna, dulce, se arrodilla sobre el canto [...] "(97), "La vida, grita, hermanos, en lo profundo del mundo y de nosotros mismos" (42). La vida grita, nos dice Ortiz, y la poesía, que aparece siempre en sus poemas como un espíritu femenino, como "Ella", la poesía, es la encargada de tejer, anudar, hilar esas voces, esos murmullos, esos gritos, para en una trama infinita, armonizar- 
los con los de los otros hombres. La poesía según nos lo muestra Juan L. Ortiz en su poema "Ella...", en el que delinea su poética, busca la armonía, el equilibrio; a pesar de la fragmentación, a pesar del dolor y el sufrimiento, "Ella", la poesía, en un acto de amor, busca la comunión entre los hombres:

Ella...

Ella anuda hilos entre los hombres

y lleva de aquí para allá la mariposa profunda

—ala del paisaje y del alma de un país, con su polen...

Ella hace sensible el clima de los días, con su color y su perfume...

a su pesar, muchas veces, como bajo un destino.

Testimonio involuntario, ella,

de un cierto estado de espíritu, de un cierto estado de las cosas, en que la circunstancia de su hálito...

Pero se dirige siempre a un testigo invisible, jugando naturalmente con la tierra y el ángel, el infinito a su lado y el presente en el confín...

Mas es el don absoluto, y la ternura, ella que es también el término supremo y la última esencia con las melodías de los sentidos y los símbolos y las visiones

y los latidos

para el encuentro de los abismos...

Mas tiene cargo de almas, y es la comunicación, el traspaso del ser, "como se da una flor", en el nivel de los niños, más allá de sí misma, en el olvido puro de ella misma...

Y no busca nunca, no, ella...

espera, espera toda desnuda, con la lámpara en la mano, en el centro mismo de la noche... (145). 
En la poesía de Ortiz podemos rastrear desde un principio una solidaridad con el universo entero. Como lo afirma el poeta argentino Hugo Gola en el libro Las vueltas del río: "La hermandad con todo lo creado, seres humanos, animales, árboles, y aun el mundo inanimado, seguramente fue estimulada por el pensamiento oriental, pero existían en él como una peculiaridad de su carácter. Su poesía siempre estuvo atenta al dolor y al padecimiento de todo lo viviente" (7). La poesía para Ortiz posibilita entonces la unidad, la reunificación de un mundo dividido, sufriente; pero esta unificación sólo se hace posible cuando el lenguaje se vuelve receptivo, cuando se vacía de todo discurso de autoridad, cuando renuncia a la rigidez de lo predeterminado por el ego y se hace flexible.

Pero, ¿cómo crear un lenguaje lo suficientemente dócil, dúctil, suave, ligero, que permita la fusión de los contrarios, que permita la incorporación de los elementos más heterogéneos en un solo hálito, en una misma respiración?, ¿cómo tejer todas esas voces?, ¿cómo lograr esa transparencia tan anhelada?, ¿ese vacío dispuesto a recibirlo todo?, ¿cómo lograr un poema casi silencioso, donde nada se imponga a nada y todo encuentre su lugar y siga la dirección correcta? Precisamente la búsqueda de ese lenguaje fue la apuesta de Ortiz a lo largo de toda su vida, desde sus primeros poemas hasta los últimos vemos esa necesidad de llegar a un lenguaje de extrema delicadeza. Lo sorprendente aquí no es sólo el deseo de Ortiz, sino la realización de ese deseo. Si seguimos los títulos de sus libros en orden cronológico: El agua y la noche (1933), El alba sube (1937), El ángel inclinado (1938), La rama hacia el este (1940), El álamo y el viento (1948), El aire conmovido (1949), La mano infinita (1951), La brisa profunda (1954), El alma y las colinas (1956), De las raices y del cielo (1958), El junco y la corriente (1971), El Gualeguay (1971), La orilla que se abisma (1971), ${ }^{3}$ podemos encontrar una clave importante para entender la manifestación de esa transparencia: el agua y el aire son los elementos a los que Ortiz se ciñó a lo largo de toda su obra. En sus poemas las imágenes aéreas están siempre en el

${ }^{3}$ Los trece libros mencionados arriba componen el libro En el aura del sauce, editado en vida del poeta, en 1970, por la Editorial de la Biblioteca Popular Constancio C. Vigil de la ciudad de Rosario. 
camino de la desmaterialización, casi se evaporan, son la fugacidad en sí mismas. Las imágenes del agua, por el otro lado, evocan imágenes del transcurso, del movimiento. Ambas comparten su falta de límites, su apertura, su maleabilidad. La poesía de Ortiz se apropia de la fluidez y de la ingravidez de ambos elementos, sus poemas, al igual que éstos, tienden hacia un devenir constante, un transformarse continuamente.

En ese entretejido de imágenes aéreas y acuáticas surge una serie de espejos, sombras, luces, que llevan a las palabras a formar imágenes cada vez más profundas, flexibles y abiertas. Imágenes que llevan a una poesía de los reflejos y del devenir. De entre estas imágenes surge una serie de matices que conducen a las palabras a buscar distintos puntos de contacto: "El río tiene esta mañana, amigos, / una fisonomía cambiante, móvil, / en su amor con el cielo melodioso del otoño / Los gestos de los hombres y el paso de la mujer / y el canto de los pájaros se acuerdan / con el agua y el cielo en un secreto ritmo [...]" (Juan L. Ortiz, Obra completa, 232). "[...] Qué?... / que la gota, siempre tiene el tiempo consigo / para hacer que crezcan / raíces sobre el éter, y ramas, ramas, debajo del abismo... / y todavía / para abrir las alas de la piedra... [...]" (195).

En sus libros encontramos también ciertas palabras que constantemente se repiten: río, cielo, horizonte, reflejos, alma, vapor, luz, alado, ligero, ondular, hilos, palidez, ecos, sonido, música, suspiro, plumas, perfumes, brillos, etc.; algunos seres fugaces atraviesan sus poemas: hadas, gnomos, ninfas, ángeles, y como un pintor impresionista, Juan L. Ortiz colorea sus versos con el lila de las jacarandas, con los reflejos amarillos y rosáceos del crepúsculo, con el verde de los árboles y el azul, el blanco y el gris del cielo. Juan L. Ortiz se da a la tarea de crear una atmósfera apropiada para recibir y poder registrar lo que a él más le interesa: los matices, las progresiones, los procesos, la sutileza de los sonidos, la experiencia de lo fugaz, las variaciones de la luz, las mutaciones del río, las correspondencias e interrelaciones de la naturaleza: "Un grillo, sólo, que late el silencio. / A su voz se fijan / los resplandores / errátiles / de las estrellas / que tienden hilos vagos / al desvelo / de las flores, las hierbas, los follajes?" (28).

Como un maestro zen, Ortiz logra, en sus poemas, la mayor destreza técnica y la máxima fluidez: construye una compleja red de palabras en 
la que intenta pulverizar el sentido. Aunque resulte paradójico, en sus últimos libros, Ortiz, a través de la saturación de ciertos recursos, llega al vacío, a esa tan anhelada transparencia. Hugo Gola en el prólogo a En el aura del sauce, ahonda sobre esto:

Ortiz sospecha que los idiomas occidentales, tan rígidos y lineales, han sido creados "como para dar órdenes". Para él sólo el ideograma chino, tan próximo a la música, constituye un instrumento apto para captar los estados variables, indefinidos, contradictorios, imprecisos del sentimiento poético. Imposibilitado de usarlo, Ortiz se esmeró por restarle gravedad a su lengua, por aliviarla de todo peso. Para ello eliminó las estridencias, apagó los sonidos metálicos, multiplicó las terminaciones femeninas, disminuyendo la distancia entre los tonos, aproximándose al murmullo (15).

Tendríamos que hablar también de su constante uso de adverbios indefinidos, dubitativos, interrogativos, que interrumpen continuamente sus versos, o del alargamiento de ciertos sustantivos que adverbializa: crepuscularmente, rilkeanamente, jardinadamente, transcielamente, otoñalmente, altísimamente, septendrinamente: “[...] Hay, pues, Stefan George, [nos dice Ortiz] algún momento, en realidad, que de todo de sí / cuando al curvar, jardinadamente, un recuerdo de círculo, / deja caer un eco, diríamos, / de uno de sus pétalos sobre la propia palidez también en ida [...]" (224). Importante es, además, señalar el uso de los puntos suspensivos, de las interrogaciones que se abren sucesivamente siempre aplazando o suprimiendo el sentido, como si Juan L. Ortiz no quisiera afirmar o negar nunca de manera rotunda y prefiriera sugerir, aludir, señalar, o incluso callar. Los tanteos, las vacilaciones, la apertura, el alargamiento, todo tiende a que en los poemas de Ortiz se adelgace el sentido.

Sin embargo, nos advierte Hugo Gola: "todo este empeño formal no constituye un mero ejercicio técnico, un alarde, más o menos equidistante del peligro, sino un riesgo absoluto de índole moral. Porque es precisamente aquí donde el poeta revela su verdadero compromiso" (15). No es extraño entonces que Juan L. Ortiz haya elegido intuitivamente el agua como la sustancia primordial de su poesía; tanto para el taoísmo como para el budismo zen, el arte de la vida reside en la continua readaptación al entorno: ceder y seguir el propio cauce. Pero ceder, o en 
palabras de Ortiz "ser humilde", supone una apuesta en el plano ético. La humildad es lo contrario del egoísmo, es lo que le permite al hombre sentir con los demás y comprender su corazón: “¿Dónde está mi corazón, al fin. / Ah, mi corazón está en todo. / En las vidas más increíbles, próximas y lejanas. / Está en las más hermanas de aquí y de allá, caídas o / incorporadas [...]" (81). Para Juan L. Ortiz la piedra angular del sentimiento poético es la sinceridad, la fidelidad a uno mismo; ese sentido ético lo lleva a incorporarlo todo y a incorporarse en el todo, lo lleva a pensar en un "vivimos" antes que pensar en un "vivo", y ese "vivimos" implica un compromiso, ese "vivimos" implica también un vivir(se) en los otros y desde los otros. Conocer, en esta dimensión, significa volverse el otro, fundirse en el otro, suspender el propio juicio para sentir lo que el otro siente. Juan L. Ortiz, retomando la idea de la "capacidad negativa" del poeta romántico inglés John Keats, comenta:

Keats decía que el poeta era el hombre que no podía tener personalidad porque se identificaba con aquello que tenía que decir, con lo que necesitaba decir. El poeta se pierde, muere también en ese sentido como individuo [...], en tanto se identifica con todo. El individuo debe morir como individuo para poder ser persona, en un sentido que persona significa una categoría mucho más que individuo, es una categoría mucho más comprensiva, un estado más comprensivo, en que el individuo está penetrado por el otro, no sólo el tú sino el Otro en un sentido espiritual aunque no sea absoluto, y ya no ante lo visible sino también ante lo invisible (Bignozzi).

Los vínculos entre esa "capacidad negativa" a la que alude Ortiz y la visión zen del satori son muy sugerentes. Casi al inicio del discurso que pronunció el escritor japonés Yasunari Kawabata al recibir el Premio Nobel de Literatura en 1968, encontramos un poema (waka) del bonzo Myoe (1173-1232):
Mi corazón
resplandece, pura
expansión de la luz y
sin duda la luna piensa
que la luz es suya 
En su comentario al poema del bonzo Kawabata dice: "Viendo la luna, se convierte en la luna, la luna vista por él llega a ser él. Él se sume en la naturaleza, se hace uno con ella. La luz del claro corazón del bonzo, sentado en la sala de Meditación antes del alba, llega a ser para la luna del alba su propia luz" (418). Satori, dicen los maestros zen, es volver a nuestra naturaleza; a nuestra naturaleza de flor, de luna, de nube, etc. Al igual que el bonzo Myoe, Juan L. Ortiz, en pleno siglo Xx, vuelve continuamente a su naturaleza para reencontrar la armonía perdida. Su poesía es consecuencia de un estado de contemplación similar al de la meditación del bonzo; ambos renuncian a sí mismos para compenetrarse con lo otro, para compenetrarse con el mundo. Pero esa comprensión intuitiva "no surge cuando un mundo de vacuidad es asumido fuera de nuestro cotidiano mundo de los sentidos; pues estos dos mundos, sensible y suprasensible, no están separados, sino que son uno" (Suzuki, 163). El poeta, entonces, despierta al mundo a partir de los sonidos, colores, texturas, movimientos. Contemplación es atención total a todo lo que sucede. Sólo a través de la contemplación, nos diría Ortiz, se pueden percibir los movimientos cotidianos, el nacimiento de las flores, el temblor de las yerbas, el susurro del viento en los ramajes, los hondos reflejos. Mientras Myoe, el bonzo japonés, se funde con la luz de la luna, Juan L. Ortiz se hace uno con el río. Me parece que el comentario de Kawabata al poema del bonzo puede iluminar también este poema de Juan L. Ortiz con el que cierro mi texto:

Fui al río...

Fui al río, y lo sentía

cerca de mí, enfrente de mí.

Las ramas tenían voces

que no llegaban hasta mí.

La corriente decía

cosas que no entendía.

Me angustiaba casi.

Quería comprenderlo, sentir qué decía el cielo vago y pálido en él 
con sus primeras sílabas alargadas, pero no podía.

Regresaba

— ¿Era yo el que regresaba?-

en la angustia vaga

de sentirme solo entre las cosas últimas y secretas.

De pronto sentí el río en mí,

corría en mí

con sus orillas trémulas de señas,

con sus hondos reflejos apenas estrellados.

Corría el río en mí con sus ramajes.

Era yo un río en el anochecer,

y suspiraban en mí los árboles,

y el sendero y las hierbas se apagaban en mí.

Me atravesaba un río, me atravesaba un río!

Nota

Juan Laurentino Ortiz nació el 11 de junio de 1896 en Puerto Ruíz, Departamento de Gualeguay, Provincia de Entre Ríos, Argentina. Salvo dos años en Buenos Aires, pasó toda se vida en su provincia natal: en Gualeguay hasta 1947, y en la ciudad de Paraná hasta su muerte. Su primer libro de poesía, El agua y la noche, apareció en 1933. En el aura del sauce, Ed. Biblioteca, Rosario, 1970, reúne toda su poesía hasta ese momento. Murió en 1978 (Referencia tomada de la revista Poesía y poética 18, número especial dedicado en su totalidad a Juan L. Ortiz). En 1996 salió editada por el Centro de Publicaciones, Universidad Nacional del Litoral, Santa Fe, Argentina, la Obra completa de Juan. L Ortiz.

\section{REFERENCIAS}

Gola, Hugo, Las vueltas del río: Juan L. Ortiz y Juan José Saer, México, Mangos de Hacha, 2010. 
KaKuZo, Okakura, El libro del té, trad. Esteve Serra, España, José J. de Olañeta, 2011.

KawABATA, Yasunari, "El Japón, su belleza y Yo", discurso de Kawabata al recibir el Nobel, en Javier Sologuren, Obras completas, tomo IV, trad. Javier Sologuren, Lima, Pontificia Universidad Católica del Perú, 2004.

Ortiz, Juan L., En el aura del sauce, México, Universidad Autónoma de Puebla, 1987.

OrTIZ, Juan L., Obra completa, Argentina, Centro de Publicaciones, Universidad Nacional del Litoral, 1996.

Reps, Paúl (comp.), Carne Zen, Huesos Zen, Argentina, Editorial Troquel, 1994.

Suzuki, Daisetz T., El zen y la cultura japonesa, trad. María Tabuyo y Agustín López, España, Paidós, 1996.

Entrevistas a Juan L. Ortiz

"Juan L. Ortiz en el límite, entrevista de Jorge Conti", Poesía y poética 18, México, Universidad Iberoamericana, 1995.

"La poesía que circula y está como el aire, entrevista de Juana Bignozzi", $<$ http://ustedleepoesia2.blogspot.mx/> [05/04/2013]. 